\title{
APUNTES SOBRE LA FILOSOFÍA DE DIONISIO (PSEUDO-)AREOPAGITA'
}

\author{
Christian Schäfer \\ Universität Regensburg (Alemania)
}

\begin{abstract}
RESUMEN
Desde hace más de un siglo, la filosofia de Dionisio el Areopagita ha sido menospreciada y subestimada como poco original debido a su obvia dependencia del pensamiento de Proclo. El presente artículo se propone corregir este punto de vista denigrante y re-evaluar el sistema neoplatónico presentado por Dionisio en el tratado De divinis nominibus. Al abstenerse metódicamente de leer a Dionisio como mero plagiario de Proclo, esta interpretación de los escritos dionisianos nos presenta su filosofía como la elaboración original y profunda de una teo-ontología que - en las palabras del poeta Samuel T. Coleridge- «emprende la tarea de explicar la totalidad de las cosas estrictamente a través de un análisis de la autoconciencia, y a la vez construye en la mente un entero cosmos sirviéndose de nada más que de elementos proporcionados por la mente misma».
\end{abstract}

Palabras clave: Dionisio (el Areopagita), Proclo, Neoplatonismo, Ontología.

\begin{abstract}
For his obvious dependence on certain parts of Proclean philosophy, Dionysius the Areopagite has been neglected as a philosopher in his own right for more than a century. The present article tries to (at least partly) re-evaluate and to reassess our view of Dionysius's Neoplatonic system as depicted in the treatise De divinis nominibus. It is above all in a 'naive' methodical disregard of the Proclean background that the (Pseudo-) Areopagite's philosophy turns out to be a novel view and a valuable account of an intricate Platonic theo-ontology which -in Coleridge's famous words- «endeavours to explain all things by an analysis of consciousness, and builds up a world in the mind out of materials furnished by the mind itselfy.
\end{abstract}

Key words: Dionysius (the Areopagite), Proclus, Neoplatonism, Ontology.

Hablar sobre Dionisio 'el Areopagita' significa hablar sobre un autor que no conocemos como persona histórica. Lo que se sabe, es esto: desde los inicios del siglo VI d.C., aparece y se lee en la iglesia de Oriente, y mucho más tarde también en el Oeste ${ }^{2}$, un conjunto de escri-

1 Se trata de una versión ampliada y retocada de una conferencia que tuve el placer de dar como parte del Curso de Extensión 'Filosofia Medieval' organizado por la Universidad Nacional de Colombia y la Universidad de los Andes en Bogotá en septiembre del 2002. Perdónenseme algunos tropiezos estilísticos debidos, en su mayoría, al carácter de exposición oral originario. Agradezco a Andrés Quero Sánchez sus correcciones y sugerencias.

2 Sobre la primera aparición del texto, su recibimiento y crítica inmediatos, así como la trayectoria y tradición filosóficas de los escritos en el Oeste y en el Este respectivamente, cf. B.R. Suchla, Textprobleme der Schrifi

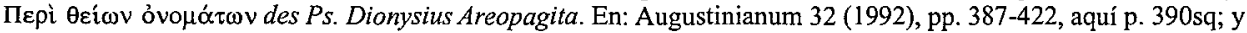
E. Jeauneau, Denys l'Aréopagite, promoteur du néoplatonisme en Occident. En: L.G. Benákis (ed.): Neoplatonisme et philosophie médievale (Actes du Colloque international de Corfou 6-8 octobre 1995 organisé par la Société Internationale pour l'Étude de la Philosophie Médiévale), Turnhout 1997, pp 1-23. 
tos cuyo autor de una manera u otra parece pretender ser un discípulo directo del Apóstol San Pablo. Leemos en los Hechos de los Apóstoles 17,22-34 que San Pablo, con su famoso sermón sobre el 'Dios desconocido' en Atenas, causó tanta impresión en cierto número de sus oyentes griegos, que algunos de ellos le siguieron para que les enseñara más sobre su 'doctrina'. Entre los que se le juntaron, se nombra en primer lugar un cierto Dionisio, denominado el Areopagita $(17,34) \multimap$ o sea, un jurista de la corte de Atenas que tenía su sede en la colina llamada Are-

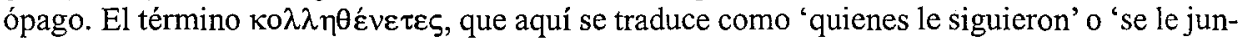
taron', tiene un significado más intensificado, sin embargo, en el habla de la época, y prácticamente de término técnico: expresa que los así denominados se adhirieron a la doctrina expuesta por el Apóstol y que optaron por la forma de vivir y creer de los cristianos, al igual que se hacía en aquellos tiempos al decidirse por una escuela filosófica, su forma de vida compartida y pensar unánime. No es por coincidencia que poco antes $(17,18)$, el autor de los $\mathrm{He}$ -

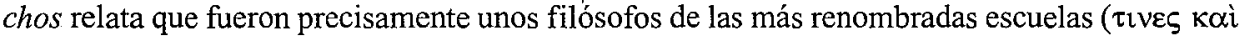



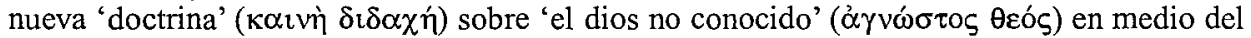

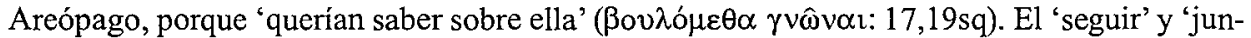
társele', la 'doctrina' que despierta el interés de los discípulos de las mayores corrientes filosóficas, el afán por la $\gamma \nu \omega \hat{\sigma} \sigma \varsigma$ que San Pablo provoca en ellos etc., todo esto sumerge la deci-

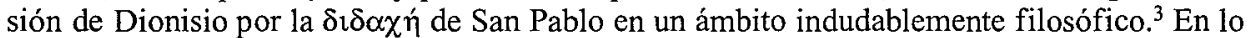
que sigue, pondré mucho cuidado en no subestimar y en tomar muy en serio este 'setting' que antecede y nutre constantemente la doctrina (si así se la puede llamar) de los escritos que llegaron a nosotros con la pretensión de ser obra del 'Areopagita Dionisio'.

\section{1.}

Alrededor del el año 528 d.C., por primera vez el nombre del 'Areopagita Dionisio' es mencionado como el del autor de un conjunto de cuatro tratados y diez epístolas: el denominado Corpus Dionysiacum (CD). El contenido de estos catorce escritos es marcadamente platónico, al estilo del neoplatonismo tardío con su especial interés en la experiencia mística y en la detallada jerarquización de los seres celestiales -0 , por lo menos, incorpóreos. Ambos rasgos se encuentran en el CD integrados en un complicadísimo sistema teológico cristiano.

En el presente artículo, quiero enfocar esta relación entre filosofia neoplatónica y teología cristiana en el tratado Sobre los Nombres Divinos. Pero antes no estará de más decir unas cuantas palabras sobre la supuesta identidad del autor. Las primeras dudas acerca de la autenticidad de los escritos que conforman el $\mathrm{CD}$, o mejor dicho, acerca de su antigüedad y de su procedencia de tiempos apostólicos, surgieron ya en el mismo siglo VI, poco después de su primera mención. En efecto, parece que no existe autor ni fuente textual antes del siglo VI que mencione los escritos atribuidos al Areopagita Dionisio. Las dudas se mantuvieron durante toda la 'Edad Media' y se intensificaron durante el Renacimiento y en la época de la Reforma protestante. Sin embargo, como faltaban pruebas contundentes en contra de la edad apostólica, hasta finales del siglo XIX había quienes defendían la posibilidad de que el autor fuera el Are-

3 Como es sabido, San Agustín, al exponer las verdades cristianas ante las interrogantes filosóficas de su tiempo, se sirve de la palabra doctrina para denominar la fides quae que defiende. De doctrina cristiana se titula el opúsculo correspondiente. La fe cristiana, antes de ser una religión, es una doctrina de vida compartida, de cosmovisión, culto y devoción compartidos que a los ojos de los cristianos mismos tiene más paralelismos con las escuelas filosóficas contemporáneas que con las religiones de su época. Es por eso que otro opúsculo Agustiniano, De vera religione, no trata tanto sobre la verdad del cristianismo en comparación con la falsedad de las 'otras' religiones, sino más bien sobre la forma correcta y verdadera de la devoción (religio) que debe acompañar la doctrina. 
opagita discípulo de San $\mathrm{Pablo}^{4}$, a pesar de la filosofia tardíamente platónica presentada en el Corpus que no cuadraba con la supuesta fecha de composición en tiempos apostólicos. ${ }^{5}$

Pero finalmente, durante la última década del siglo XIX, varios estudios filológicos demostraron que diferentes trazos del tratado Sobre los Nombres Divinos eran plagios de obras menores del filósofo neoplatónico Proclo, que enseñaba y escribía como 'rector' de la escuela neoplatónica de Atenas en el siglo V. ${ }^{6}$ De modo que hoy en dia hay una ancha e insacudible base consensual sobre que los escritos tradicionalmente atribuidos a Dionisio el Areopagita datan más bien del siglo V o VI y pertenecen a un autor cristiano de alta erudición filosófica, íntimo conocedor de la obra de Proclo, y cuyo nombre desconocemos por completo. Vale añadir que de las varias y muy entretenidas conjeturas que se han hecho para descubrir el incógnito del (desde entonces: Pseudo-) Dionisio, ninguna ha sido convincente aún. ${ }^{7}$

Antes de abordar un examen del texto dionisiano, quisiera dejar constancia de dos cosas al respecto de lo que acabo de exponer:

1. El gran impacto que tuvieron la teo-ontología y la mística de Dionisio en el pensamiento de la Edad Media, no se explica exclusivamente por el peso autoritativo que les confirió el pseudónimo y la pretensión de ser obra de un discípulo directo de San Pablo. La impresión causada por el pensamiento dionisiano en egregios maestros como Eriúgena, Alberto Magno, Tomás de Aquino (¡quien cita a Dionsiso con más frecuencia que a Aristóteles!) y muchos otros más bien tiene que ver con las ideas expuestas por Dionisio y con la ejemplaridad con que logra combinar el raciocinio filosófico con el material textual de las Sagradas Escrituras. ${ }^{8}$

2. Por más espectacular que haya sido el descubrimiento, o tal vez mejor: el desvelamiento que las obras dionisianas dependen de y presuponen a Proclo: ese descubrimiento no le ha hecho ningún bien a la interpretación académica de los textos del 'Pseudo-Dionisio' en los últimos cien años. De hecho, desde entonces siempre y ex-

4 Entre ellos, C. Schneider, Areopagitica, Ratisbona 1884; y J. Parker en la introducción a su The Celestial Hierarchies of Dionysius the Areopagite, Londres 1984. Cf. al respecto el estudio de A. Louth, Denys the Areopagite, Wilton 1989, p. 15.

5 Acerca de la discusión sobre la identidad del autor y el valor doctrinal del corpus, cf. los estudios y las interpretaciones referentes en: B.R. Suchla, Verteidigung eines platonischen Denkmodells einer christlichen Welt, Gotinga 1995, pp. 12sqq; H. Koch, Proklus als Quelle des Dionysius Areopagita in der Lehre vom Bösen. En: Philologus 54 (1895), pp. 438-454, especialmente pp. 438sqq (ambos enfocan la respuesta inmediata de los eruditos bizantinos como Juan de Scitópolis); H.-U. von Balthasar, Herrlichkeit. Eine theologische Ästhetik, Vol.2, Einsiedeln 1962, p. 154, y R.J. Henle, Saint Thomas and Platonism, La Haya 1970, pp. 383 (sobre la influencia y el recibimiento de la obra disonisiana en la alta escolástica); D. Luscombe, Denis the Pseudo-Areopagite in the Writings of Nicholas of Cusa, Marsilio Ficino and Pico della Mirandola. En: L.G. Benákis (ed.): Neoplatonisme et philosophie médievale (Actes du Colloque international de Corfou 6-8 octobre 1995 organisé par la Société Internationale pour l'Étude de la Philosophie Médiévale), Turnhout 1997, pp. 93-107 (sobre el papel de la teología y filosofia dionisianas en el Renacimiento, empezando por Nicolás de Cusa); finalmente, K. Froehlich, Pseudo-Dionysius and the Reformation of the $16^{\text {th }}$ century, en la introducción a la traducción inglesa del $\mathrm{CD}$ por $\mathrm{C}$. Luibheid (Dionysius: The Complete Works, Nueva York 1987), pp. 33-46 (sobre la reacción de la Reforma protestante a Dioniso). Consúltense también las diferentes ponencias sobre el tema resumidas en: Y, de Andia (ed.), Denys l'Aréopagite et sa postérité en Orient et en Occident, Paris 1997.

6 Las intervenciones decisivas, editadas el mismo año, pero independientes la una (teológica) de la otra (filológica) en el proceso de investigación y elaboración, fueron: J. Stiglmayr, Der Neuplatoniker Proklus als Vorlage des sogenannten Dionysius Areopagita in der Lehre vom Übel. En: Historisches Jahrbuch 16 (1895), pp. 253-273 y pp. 721-748; y H. Koch, Proklus als Quelle des Dionysius Areopagita in der Lehre vom Bösen. En: Philologus 54 (1895), pp. $438-454$.

7 Una lista de posibles candidatos que se han barajado es presentada por L.G. Benákis, L'état actuel des recherches dionysiennes. En: Diotima 23 (1995), pp. 17-24. De todos modos, tal vez convenga más llamarle al autor del CD 'Dionisio (Pseudo-)Areopagita' antes que 'Pseudo-Dionisio'.

8 Así lo perciben, y correctamente, según mi criterio, Luscombe, von Balthasar y Suchla en los estudios citados en la nota 5 . 
clusivamente se le ha leído a Dionisio como un mero plagiario de Proclo sin ninguna originalidad, como una especie de Proclo cristianizado a medias, y se ha dejado que el 'Pseudo-' opaque por completo a 'Dionisio', y; con eso, la filología al autor. La mayoría de los intérpretes que hoy en día encuentran dificultades en entender a Dionisio (y prácticamente no hay quien no las tenga), recurren al remedio de leer a Proclo para de esta lectura de Proclo derivar su exégesis de los textos dionisianos. ${ }^{9}$

En lo que sigue, quiero evitar tales lecturas secundarias y desviadas aproximaciones a fin de proponer otro método: a saber, regresar, en la medida de lo posible, a una lectura un tanto 'ingenua' de los textos dionisianos sin recurrir constante y compulsivamente a su dependencia histórica de Proclo. En cambio, quisiera aceptar metódicamente (iy nada más que por razones metódicas!) la ficción dionisiana de la composición de estos textos por un discípulo de San Pablo y en el primer siglo d.C. (Por ello, tampoco usaré el prefijo 'Pseudo-' al referirme al autor). Esto, más que nada, porque creó que esta ficción literaria o estilística tiene su sentido y cierta influencia en el contenido de las obras de Dionisio. El pseudónimo, más que usurpar indebidamente alguna autoridad apostólica, quiere decirnos algo sobre las intenciones, el mensaje, y los presupuestos del pensamiento expuesto en ellas. Lo cual no quiere decir que no acepte que este pensamiento sea plenamente neoplatónico. Desde los primeros comentaristas bizantinos hasta en las apostillas de Tomás de Aquino y Nicolás de Cusa, nunca surgieron serias dudas acerca de que la filosofía del supuesto Areopagita era netamente platónica. Pero la clave para entender a Dionisio no está en hacerle el títere cristiano de su maestro Proclo. Al contrario: la clave para interpretar los escritos dionisianos se halla en aceptar la ficción literaria de leer a un autor que, educado en la cultura pagana de la Atenas en los tiempos de Cristo, se encuentra con la doctrina cristiana promulgada por San Pablo Apóstol. Es precisamente esta 'ingenuidad', ese entusiasmo y esa inmediatez del primer encuentro entre la altamente avanzada y venerable filosofia pagana y el cristianismo naciente directamente transmitido por los Apóstoles que la ficción estilística quiere recrear saltándose algunos siglos para atrás y poniendo en boca de un converso griego de primera hora lo que en el siglo VI ya sería una refinada y muchas veces repetida rutina intelectual: esclarecer el tan apasionadamente debatido problema de la fusión de las verdades cristianas con la sabiduría mundana como si fuera un testigo ocular del debate de San Pablo con los filósofos atenienses en el Areópago.

2.

Dadas estas circunstancias y tomadas las debidas precauciones metódicas, mi propósito aquí será escrutinar un sólo tratado de la obra dionisiana. Es el más extenso y filosóficamente más importante de los cuatro, titulado De divinis nominibus o Sobre los Nombres Divinos (DN) ${ }^{10}$ La interpretación requiere dos avisos previos - dos por lo menos:

1. El 'nombre divino' o 'teónimo' no es simplemente una denominación, una referencia exterior, o indicación léxica de Dios. Más bien, parece que hay que tomar la palabra 'nombre' en su sentido bíblico, en el sentido que sugieren expresiones como «no tomarás en vano el nombre de Dios» (Ex 20,7), el «santificado sea tu nombre» del Padre Nuestro, o el bautismo «en el nombre de Jesús». Todos estos pasajes apuntan a que el

9 He tratado de esclarecer unos cuantos puntos en contra de esta lectura 'secundaria' del texto dionisiano en C. Schäfer, Unde Malum. Die Frage nach dem Woher des Bösen bei Plotin, Augustinus und Dionysius, Würzburg 2002, pp. $402-405$ y $466-469$.

10 Las ediciones estándar son, por supuesto, las del Tomo III de la venerable PG y la brillante nueva edición crítica: (Pseudo-) Dionysios Areopagites, De divinis nominibus [Corpus Dionysiacum I] (ed. B.R. Suchla), Berlín/Nueva York 1990. En esta última edición de Gotinga-Berlín, las demás obras dionisianas se publicaron en: (Pseudo-) Dionysios Areopagites, De coelesti hierarchia. De ecclesiastica hierarchia. De mystica theologia. Epistulae [Corpus Dionysiacum II] (eds. G. Heil y A.M. Ritter), Berlin/Nueva York 1991. Las referencias al texto de DN se harán según la forma de citación estándar de la PG. 
'nombre', dentro del lenguaje bíblico-teológico, significa el ser mismo del nombrado: no hay que insultar a Dios mismo, hay que santificar la persona divina misma, el bautismo nos hace partícipes de la condición esencial de Jesús de ser hijo de Dios, etc. El teónimo en Dionisio, entonces, más que ser una mera denominación, indica la esencia y el ser mismo de Dios, ya que el 'Nombre' aquí viene cargado de tales reflexiones teológicas. En esta acepción del concepto de 'nombre', tratados Sobre los nombres Divinos han tenido gran trayectoria en la teología medieval a través de los siglos - los últimos de los más célebres datan del siglo XIV-. Hay que tener este concepto de 'nombre divino' o 'teónimo' bien claro. ${ }^{11}$

2. Al tratar el escrito dionisiano DN pretendo, en lo siguiente, ofrecer una interpretación integra de la filosofia del Areopagita. A primera vista, sin embargo, el tratado parece ser enteramente teológico (y prima facie, el tema de los teónimos en el sentido mencionado también lo sugiere así). Lo cual por un lado es un consabido problema que acompaña - pero también alienta - toda la filosofía medieval. Por otro lado, estoy convencido que en Dionisio se pueden separar perfectamente los rasgos filosóficos de los teológicos. Más precisamente, la teología del tratado DN se apoya en una elaborada ontología que le sirve de esqueleto. Trataré entonces de (por así decir) 'deshuesar' —o radiografiar - el texto para aislar el esquema filosófico subyacente. El problema se presenta un poco como en la parábola evangélica de la maleza entre el trigo (Mt 13,24-30): es fácil discernir el trigo de la maleza; sin embargo, muchas veces no se puede quitar la maleza sin arrancar también el trigo. Lo mismo en el tratado dionisiano: sólo se le puede leer como un compacto conglomerado filosófico-teológico, como una teo-ontología. La interpretación, en cambio, puede separar estos aspectos metódicamente y aislar el esquema filosófico detrás de los contenidos teológicos, si bien siempre hay que cuidarse de no arrancar ambos al tratar de separar el uno del otro. $^{12}$

- De todo ello se deriva el siguiente plan de exposición para mi humilde intento de esbozar la filosofia de DN:

- Primero, dar a conocer los teónimos y su distribución por los trece capítulos del tratado.

- Después, revisar brevemente el plan filosófico de la obra dionisiana.

- Tercero, comparar este patrón o paradigma filosófico con la lista de los teónimos para probar (y comprobar) que los nombres divinos expuestos por Dionisio siguen y reflejan su estricto plan ontológico de índole platónica.

- Finalmente, una vez reconstruida la ontología dionisiana a través de los nombres de Dios, revisar más detalladamente dos de estos teónimos, Paz y Justicia.

3.

Vayamos por pasos:

Los teónimos presentados y tratados por Dionisio en $\mathrm{DN}$, a primera vista no parecen tener conexión entre sí, menos aún seguir un elaborado plan o diseño. Además, se encuentran esparcidos por los trece capítulos de la obra sin orden obvio. He aquí la lista:

11 Dicho sea entre paréntesis y por el momento solamente como una conjetura entre otras: esta acepción de 'nombre' tal vez podría ayudar para un mejor entendimiento del pseudónimo del 'Areopagita': el 'nombre' expresa mucho más que un apellido o un nombre de artista; expresa una actitud interior que define a quien escribe y una identidad filosófica o espiritual a través de la cual el autor quiere ser reconocido y leído. Volveré sobre esta peculiaridad al final de este artículo.

12 Póngase cuidado en el tertium comparationis: no pretendo identificar la teología con la maleza sino en este único aspecto, y sólo en cr orefiere al tema tratado aquí. 


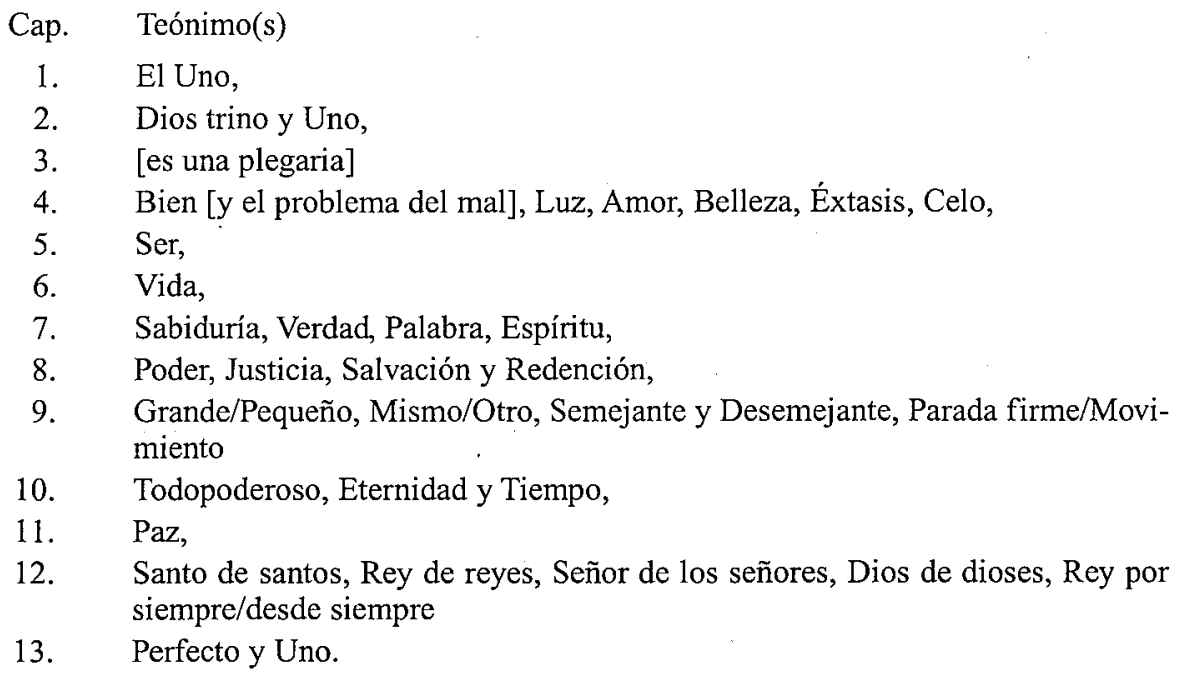

Por lo menos, hay una cosa que todos estos teónimos tienen en común: están todos extraídos de la Biblia. Algunos más obviamente (como 'el Camino, la Verdad y la Vida'), otros de una manera un tanto rebuscada como lo es el caso de la 'Pequeñez' y de la 'Desemejanza' en el capítulo 9. De hecho, la 'pequeñez' es atribuida a Dios en un extraño pasaje del primer Libro de los Reyes $(19,12)$, mientras que Dionisio deriva la 'desemejanza' divina de la primera Epistola a los Corintios $(15,28)$. De igual manera, el origen bíblico de todos los demás teónimos dionisianos puede ser establecido. ${ }^{13}$ - En el capítulo 9 , además, se identifica otra fuente de los teónimos discutidos, que, típicamente para Dionisio, concuerda con la fuente bíblica: los nombres divinos que encontramos en este capítulo están todos extraídos del diálogo Parménides de Platón (137c-166c). Un diálogo, cuya segunda parte se nos presenta como un perturbante estudio sobre la anulación de (¿todas?) las contradicciones en el ámbito transcendental (o por lo menos, así lo quisieron entender los sucesores de Platón). Ya en esta obvia manera de paralelizar la terminología bíblica con la nomenclatura platónica, se vislumbra el gran esfuerzo y el ambicioso proyecto dionisianos de armonizar y aun unificar pensar cristiano y filosofia griega. (Nótese que Dionisio lo hace justamente a través de los términos que los platónicos empleaban para describir la coincidencia final de los contrarios.)

4.

Por ello, hay que volver la mirada al sistema filosófico retomado, asimilado y elaborado por Dionisio. Ya a primera vista, se revela su carácter marcadamente (neo)platónico: básicamente, se trata de un ambicioso esfuerzo de deducir racionalmente la realidad entera desde un solo supuesto, el famoso 'Uno' omnitrascendente. Este 'Uno'/'Ev, identificado por Dionisio con el Dios único y creador de la Biblia, ya no tiene causa ni explicación más allá de sí mismo, siendo, a la vez, la causa exclusiva y total de todos los seres. He aquí un punto importante: Dios/el 'Uno', en esta perspectiva no pertenece al ámbito del ser, sino es concebido como más

13 Las respectivas referencias bíblicas se hallan puestas en listas y orden en el aparato crítico de la traducción de las Obras completas del Pseudo Dionisio Areopagita por T.H. Martín-Lunas, Madrid ${ }^{2} 1995$. 
allá del ser. ${ }^{14} \mathrm{El}$ ámbito del ser, en cambio, es definido como el conjunto o la totalidad de lo que es causado (o 'creado') por la Causa transcendental, positivamente meóntica ${ }^{15}$, o hiperóntica.

De este breve esbozo del planteamiento básico subyacente a la filosofía dionisiana, ya se desprenden los dos grandes problemas que esta filosofia se propone y trata de resolver con mucho rigor especulativo:

Primero: cómo concebir y hablar sobre la primera Causa de todo si ésta se encuentra más allá del ser y cuando, como Dionisio enuncia repetidamente ${ }^{16}$, el pensar humano, a su vez, sólo se puede fijar en cosas que son, que caen dentro del ámbito de lo que es.

Segundo: cómo explicar que de una causa que estrictamente no es, se derive todo el universo existente; que de la primera Causa estrictamente una se derive la multiplicidad de los seres; que algo que no conocemos sea la explicación de todo lo que conocemos. ${ }^{17}$

En el tratado DN, Dionisio aborda ambos problemas en este mismo orden. El primero, en los tres capítulos introductorios del escrito:

Su tema es el misterio del Dios trino y uno y la imposibilidad de desentrañar este misterio. Consta la inefabilidad de Dios. ${ }^{18}$ No se puede entender el misterio Divino por sí, pero parte del misterio Divino es el hecho de la autoentrega total de Dios en el acto de crear por amor. O sea: no tenemos los medios gnoseológicos para acceder a la Causa hiperóntica. Lo que conocemos de esta Causa, sin embargo, son sus efectos, lo causado por ella y por nada más que ella. Lo que conocemos de ella es cuanto de ella permanece en sus efectos. Lo cual ya es mucho considerando su total inefabilidad. ${ }^{19}$ Por ende, para hablar sobre Dios (el Inefable) el único camino humanamente accesible consiste en hablar sobre la creación (que sí nos es conocida y que podemos aprehender, en lo básico al menos). ${ }^{20}-\mathrm{Y}$ por lo menos, una gran incógnita se re-

14 Como se ha observado muchas veces, es en esto que más marcadamente se distinguen la metafisica 'oriental' y la 'occidental' en los Padres de la Iglesia: mientras que en Occidente domina la idea de Dios como ipsum esse o plenitud del ser, en Oriente, Dios es El más allá del ser. Es posible que esto tenga que ver con los presupuestos semánticos de la ontología (sobre esto, el lector interesado podrá encontrar unas cuantas referencias e indicaciones bibliográficas en C. Schäfer, Unde Malum, p. 238). De todos modos, para Dionisio hay que tener en cuenta lo que Eric D. Perl escribe a propósito de la filosofia de Plotino: «Being is not first but derivate» (E.D. Perl, 'The Power of all Things': The One as pure Giving in Plotinus. En: American Catholic Philosophical Quarterly 71 [1997], pp. $301-313$, aquí p. 305).

15 Hago uso del adjetivo correspondiente al $\mu$ ơ őv platónico al estilo de las recientes publicaciones anglosajonas ('meontic'). - La idea de que el primer principio creador debe ser el principio constante y perdurable de todos los seres sin pertenecer a los seres, es un dogma fundamental plotiniano: cf. Enn. V.2[11].1,1.

16 Un problema que es tratado por Plotino más de una vez (v.gr. en Enn. V.5[32].6,8-11), quien a su vez lo hereda de la República de Platón (509b). El dilema platónico ante la inefabilidad del Dios de Quien sin embargo se habla constantemente, se encuentra densificado en el sobrio comentario de J.C. McLelland: «The epistemological formula is simple: human knowledge is limited to the intelligibility of being (a precious tautology); God is hyperbeing; therefore he is unknowable» (J.C. McLelland, God the Anonymous. A Study in Alexandrian Philosophical Theology, Cambridge/Mass. 1976, p. 153). En Dionsiso, el problema se repite varias veces: DN 588A: $\pi \alpha ́ \alpha \alpha 1 \zeta$

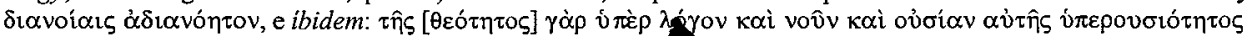


dimiento de las cosas que caen dentro del ámbito del ser; Dios, en cambio, está más allá del ser.

17 Una vez más, la pregunta se encuentra explícitamente en el 'fundador' del Neoplatonismo, Plotino: Enn. V.1.[10].6,2-8. Cf. también E.D. Perl, 'The Power of All Things', p. 302.

18 Así, por ejemplo, lo expresa en DN 588AB, DN 865C, DN 872A, etc. Como siempre, los primeros trazos explícitamente neoplatónicos de esta teología de inefabilidad se encuentran en Plotino (v.gr. Enn. V.5[32].6,24: 00

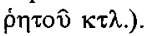

19 Cf. DN 588D, 589B-589C, DN 589D, DN 872A, y, tal vez de la manera más clara del corpus entero, en DN 645A.

20 Hágase una comparación un tanto baladí para después superarla metódicamente: nadie de nosotros conoció, ni conocía, ni conoce, a Cayo Julio César. Nunca lo hemos visto, ni hablado con él, etc. Incluso si lo pudieramos hacer a través de alguna máquina del tiempo o una paradoja cronológica, a lo mejor nunca lo entenderíamos, por no saber latín o, más probablemente, por vivir en un mundo conceptual enteramente ajeno al del cosmos romano 
suelve en el transcurso de estos primeros capítulos: la doctrina cristiana -revelada por Dios, esto es importante, no descubierta por la limitada concepción humana-, nos presenta a Dios como uno y trino, o sea, nos Lo presenta no sólo bajo la perspectiva de la unidad (de lo cual :se encarga el capítulo 1 de DN), sino también en términos de multiplicidad de las personas divinas (en el capítulo 2). El enigma de cómo la multiplicidad del mundo óntico se debe a la una causa, se hace así menos enigmático. El misterio inefable de la Trinidad curiosamente da la pauta para resolver el misterio de cómo explicar la multiplicidad derivada de la causa que es sólo una.

[Una observación entre paréntesis: Dionisio se ha hecho famoso, en parte, por dos peculiaridades estilísticas (y a la vez más que sólo estilísticas) que con él se introducen a - o se sancionan para - la teología cristiana. Se trata de las así llamadas hiper-predicaciones (Dios el Más-que-grande, el Superabundante, etc.) y la teología negativa (Dios el inalcanzable, el ya no entendible, etc. $)^{21}$. De la metodología de $\mathrm{DN}$, se desprende fácilmente el sentido de estas por llamarlas así- herramientas léxicas: la inefabilidad del Dios tan lejanamente remoto de la realidad óntica no se podía expresar sino negativamente, así declarando su completa otreidad, o hiperbólicamente afirmando su completa e hiperóntica sustracción del ámbito del ser.]

Resignándose a este método de reconocer la irrevocable inefabilidad de la primera Causa, Dionisio trata más detalladamente el segundo gran problema de cómo explicar que la totalidad de lo que es se deriva del Uno inefable: conocer a Dios a través de lo que conocemos, o sea: a través de lo causado. El problema es, por tanto, cómo entrelazar cosmovisión y teología.

Ya se nota en esto el extremo cuidado dionisiano en tratar su teología del Dios meóntico y su extremo cuidado en expresarla. Nada o poco sorprende, pues, que en el tercer capítulo de DN, Dionisio se salga de su estricto plan de exposición de teónimos bíblicos e intercale una plegaria, invocando la ayuda de Dios ante la difícil tarea de tratar y de exponer los Nombres Divinos. Sin embargo, el constante acordarse de Dios para no perder de vista el motivo del tratado forma parte de la metodología de DN (no sólo en esto, se parece también a las Confessiones de San Agustín) y que Dionisio lo anuncie con una plegaria está muy de acuerdo con su plan de composición. ${ }^{22}$

En lo siguiente, Dionisio, partiendo de su doctrina expuesta en los introductorios capítulos 1-3, describe la auto-irradiación de lo Divino. La creación, en este sistema a veces perturbantemente platónico, 'funciona' casi como (y es comparable, en lo fundamental a) un acto de reflexión mental: al reflexionar, generamos un pensamiento; lo ponemos frente a nuestra mente como si fuera algo propio, pero sin que por ello deje de ser enteramente nuestro; después de contemplarlo y evaluarlo, volvemos a integrarlo a nuestra mente, haciéndolo 'nuestro' en un

del siglo I a.C. y, en especial, al de uno de sus más altos representantes. Sin embargo, creemos poder tener una opinión acerca de Julio César: nos simpatiza o no, lo admiramos o lo detestamos. Ahora bien: no conocemos a Julio César directamente. Pero conocemos la impresión que causó en sus contemporáneos, conocemos y tal vez sufrimos o gozamos de los efectos históricos de sus hazañas, conocemos lo que nos dejó por escrito y lo que se ha escrito sobre él. O sea: conocemos lo que causó en (nos)otros. Superemos este ejemplo teológicamente: no conocemos a Dios el inefable, inconcebible y eternamente sustraido del ámbito del ser al que pertenecemos nosotros. Pero conocemos lo que Él causa, la creación (que sí cae en el ámbito del ser al que pertenecemos). Ahora bien: Dios está presente en lo que causa de una manera incomparablemente más intensificada que Julio César en los ambiguos y contingentes efectos históricos de su existencia histórica. De hecho, Dios está entera e indisminuidamente presente en su creación. Al hablar de ella, pues, sin escapatoria nos referimos a Dios, al conocerla, abrimos paso al conocimiento de Dios.

21 «Pero la manera más digna de conocer a Dios se alcanza no sabiendo», Dionisio enuncia en DN 872A; sobre las hiperpredicaciones y el empleo de términos negativos cf. B.R. Suchla, Textprobleme der Schrift Пepì $\theta \varepsilon i ́ \omega v$ ỏvouó $\tau \omega v$ des Ps. Dionysius Areopagita, p. 394sq; también el clásico P. Scazzoso, Ricerche sulla struttura del linguaggio dello pseudo-Dionigi l'Areopagita, Milano 1967.

22 Esta plegaria del tercer capítulo conlleva interesantes aspectos que he tratado de esclarecer en C. Schäfer, Unde Malum, pp. 414sqq. 
sentido ahora más consentido y consciente, y, por ende, más propio. Lo mismo en el gran proyecto metafísico de Dionisio: su ontología describe el 'acto reflexivo' de Dios, cuyo pensamiento - en la analogía establecida por este ejemplo- equivale a la creación [fase 1], la cual de este modo se puede concebir como algo 'propio' (en el sentido de 'en sí mismo') sin que deje de ser Suya (en este aspecto, 'propia de Dios') [fase 2], y que al volver a su Origen será más propiamente de Dios que antes [fase 3]. - La epistemología concomitante propuesta por Dioniso será, por lo tanto: que al entenderse perfectamente como creación, como pensamiento Divino, el ser creado capta todo lo que es conocible del Creador Quien lo piensa. ${ }^{23}$

El plan de la obra, entonces, se presenta de la siguiente manera:

En los primeros tres capitulos, se establece la teología trinitaria subyacente a las siguientes tres fases del desenvolvimeinto ontológico. Como repiten los comentaristas de Dionisio, estos tres fundamentales capítulos introductorios enseñan cómo lo que explicite conocemos de la realidad mundana se encuentra complicite en Dios y se explica por Su despliegue. - Como lo hace Nicolás de Cusa, gran admirador de la obra dionisiana, al escribir: volo dicere quod omnia illa complicite in Deo sunt Deus, sicut explicite in creatura mundi sunt mundus. ${ }^{24}$

Mientras el primer capítulo alaba el Uno-Dios y con esto liga el inicio con el fin (ya que el último capitulo también se dedicará al Uno transcendental), el segundo oscila entre la alabanza de Dios simultáneamente uno y trino, preludiendo el posterior desarrollo filosófico del autodespliegue de Dios (fase 1) y de la reunificación de este mismo despliegue (fase 2) para formar una realidad bien ordenada y estable. La plegaria del capítulo tres, en cambio, resalta el motivo del anhelo del hombre de volverse a Dios, y con esto anticipa la fase 3 de la é $\pi$ -

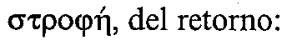

Cap. Nombre(s) Función

Desarrollo filosófico

\begin{tabular}{|c|c|c|}
\hline 1 & Uno & 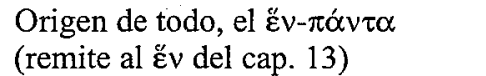 \\
\hline 2 & Dios Trino y Uno & $\begin{array}{l}\text { Despliegue (prefigura la fase 1) } \\
\text { y parádigma de unificación/ } \\
\text { recolección (prefigura la fase 2) }\end{array}$ \\
\hline 3 & [Plegaria $]$ & $\begin{array}{l}\text { re-orientación/regreso (prefigura el } \\
\text { retorno ontológico de fase } 3 \text { ) }\end{array}$ \\
\hline
\end{tabular}

MÉTODO Y PROLEPSIS

- A esto siguen los tres pasos del desarrollo metafísico en el tratado Sobre los Nombres Divinos que conforman el núcleo de la ontología dionisiana:

[fase 1]: capítulos 4-7/1 a parte:

Los teónimos correspondientes a esta fase son: el Bien, el Amor, el Ser, la Vida, la Sabiduría, la Verdad, entre otros:

$\mathrm{Al}$ auto-entregarse enteramente (por cierto, sin gastarse o diminuir), o al salirse de sí mismo, Dios es el Bien, es Amor, etc., constituyendo por su auto-irradiación una cre-

23 Cf. DN 872A: «El es todo en todas las cosas y nada entre las cosas. A todos es manifiesto en todas las cosas y no hay quien le conozca en cosa alguna. Ciertamente. Es correcto usar este lenguaje para hablar de Dios, pues todas las cosas le alaban en su relación de efectos que son de El, causa de ellas» etc. (La primera frase es una cita casi ad verbum de Plotino, Enn. V.2[11].1,1.)

24 Trialogus de possest 9,6sq. En: Nicolai de Cusa Opera Omnia XI,2, edidit R. Steiger, Hamburgo 1973. Varias otras influencias y explicaciones de la misma idea (en Dante, en Giordano Bruno) son citadas por B. Nardi, $L a$ dottrina dell'Empireo nella sua genesi storica e nel pensiero dantesco. En: B. Nardi, Saggi di filosofia dantesca, Florencia ${ }^{2} 1967$, pp. 167-214, aquí nota 182 a la p. 214. 
ación (Ser) viviente (Vida) y perfecta según Su sabia disposición de las cosas (Sabiduría). Es el mismo pensamiento místico que llevó a Santa Teresa de Ávila a definir el amor como 'la necesidad de salir de sí mismo'.

Esquematizado:

Cap. Nombre(s)

Función

Desarrollo filosófico

\begin{tabular}{|c|c|c|}
\hline 4 & $\begin{array}{l}\text { Bien, [mal], Luz, } \\
\text { Amor, Belleza, } \\
\text { Extasis, Celo }\end{array}$ & $\begin{array}{l}\text { Bondad (y sus sinónimos): } \\
\text { indicación de la extrover- } \\
\text { sión o autoentrega de Dios. }\end{array}$ \\
\hline 5 & Ser & $\begin{array}{l}\text { Escala ontológica: existir, } \\
\text { sentir, raciocinar. (cf. San }\end{array}$ \\
\hline 6 & Vida & Agustín, Proclo, Platón ${ }^{25}$ ). \\
\hline 7 & $\begin{array}{l}\text { Sabiduría, Verdad, } \\
\text { Palabra, Espíritu }\end{array}$ & \\
\hline
\end{tabular}

1a fase:

PROCESIÓN

DEL SER

[fase 2]: capítulos 7/2a parte-11/1a parte:

La creación se establece como algo propio, si bien nunca desligado de Dios; los Nombres Divinos correspondientes son: la Sabiduria (que liga esta fase a la primera), el Poder, la Justicia, Semejanza y Desemejanza, Omnipotencia, Eternidad y Tiempo, la Paz, entre otros.

La creación, en su dinámica, refleja no sólo la Sabiduría, sino también el Poder de Dios; en su imperturbado equilibrio de fuerzas y movimientos, Su Justicia; en su a veces contradictoria diversidad (Semejanza y Desemejanza), la creación sin embargo no perece, sino casi paradójicamente logra integrar y subsumir todos los aspectos, las fuerzas divergentes y los opuestos (reflejando así la Omnipotencia Divina) para formar un polifacético conjunto perfecto y estable (signo de la Paz de Dios). Es la famosa idea de la Divina reconciliación de lo irreconciliable, de la coincidentia oppositorum, tan mimada, nutrida y constantemente elaborada por los filósofos platónicos subsiguientes:

Cap. Nombre(s) Función

8 Poder, Justicia,

Salvación, Redención

9 Grande/Pequeño

Mismo/Otro

Semejante/Desemejante

Firmeza/Movimiento

10 Todopoderoso,

Antiguo/Joven

$11 P a z$
'Implicaciones' del

Uno (cf. Parménides

de Platón).

Armonía de fuerzas

y de principio y fin

resultado del detenimiento.
Desarrollo filosófico

2da fase:

RECOLECCIÓN/

DETENIMIENTO

[fase 3]: capítulos 11/2da parte-13:

Al igual que el pensamiento en el acto de reflexionar, la creación, después de haberse 'detenidamente' ordenado, sólo tiene sentido si vuelve a Quien la ha 'pensado' y puede re-integrarla a su Origen, completándola. Los Nombres de Dios que Dionisio emplea 
para la descripción de esta fase son: la Paz (que conecta esta fase a la segunda), Rey de reyes, Señor de los señores, el Perfecto, el Uno, entre otros.

El teónimo 'Paz' liga la segunda fase con la tercera, y en realidad pertenece a ambas. Al igual que la paz reconcilia los hombres entre sí (horizontalmente), también nos reconcilia con Dios (verticalmente), Rey de reyes y Señor de los señores, o sea, el Absoluto en todo lo relativo, el Uno en lo diverso y múltiple (¡la coincidencia de los opuestos!) etc.; de tal modo, partiendo de la multiplicidad y de la contingencia de lo creado, se vislumbra lo Perfecto, y se lo entiende como Único, o, en palabras de Dionisio, como el Uno que era el único Origen y ahora es la única Meta. ${ }^{26}$

Cap. Nombre(s) Función

\begin{tabular}{|cll|}
\hline 12 & $\begin{array}{l}\text { Santo de santos } \\
\text { Rey de reyes }\end{array}$ & \\
Señor de señores & esquema de inclusión reductiva: \\
Dios de dioses & 'uno en todo(s)'. \\
Rey por siemprel & \\
Desde siempre & \\
Perfecto & El fin y la perfección de \\
Uno & todo(s) es el Uno del cap. 1.
\end{tabular}

Desarrollo filosófico

3a fase:

RETORNO

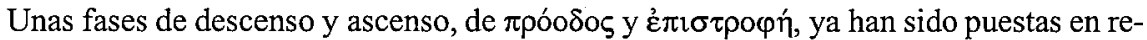
lieve por diferentes autores en varias ocasiones. ${ }^{27} \mathrm{La}$ fase de detenimiento o recolección, en cambio, la de las $\mu$ ovoí de las creaturas (DN 704C), casi nunca ha sido apreciada como tal en la mayoría de los intérpretes. En lo que sigue, voy a tratar de explicarla y de hacerla un poco más compresible como una fase esencial y bien definida del desenvolvimeinto del escalafón ontológico presentado por Dionisio en DN. De hecho, su gran dibujo de una realidad diáfana (diáfana en cuanto deja traslucir a su Creador, y velándolo lo revela) exige que - como la pelota que al rebotar en el suelo, antes de cambiar de dirección y viniendo desde arriba, vuelve hacia arriba, parece detenerse un mínimo instante - la creación antes de volver a Dios, de quien procedió, se detenga por un instante, en que el eterno reflujo ontológico se vuelva material y de este modo se establezca como lo que es: la realidad que conocemos. En este sentido por lo

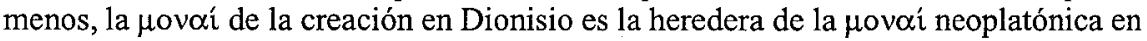
las escuelas paganas. Pero mientras que ésta es la condición para la autoirradiación, la $\pi \rho o ́ o \delta o \zeta$ de los diferentes grados de emanación en estos grados mismos, en Dionisio, en cuya filosofia los diferentes grados no producen grados subsiguientes (sino que Dios es el exclusivo Creador único de todas las cosas), la $\mu$ ovói recibe otro sentido: el detenimiento y el reposo en sí mismo de la creación denota el necesario momento de au-

26 Cf. DN 948D: «Luego, estas fuerzas [scil. de la Paz] hacen que las de rango inferior se unan consigo mismas, entre ellas, y con el único y más perfecto Principio y Autor de toda paz»; y DN 953B: la Paz «nos enseña a no guerrear en adelante ni con nosotros mismos ni con los prójimos ni con los ángeles» etc. Compárese el mismo tema en San Agustín: la paz tiene un triple poder de unión y reconciliación: con Dios, con el prójimo, y consigo mismo (De civitate Dei XIX 14; PL 41,624sq). Así también lo entendió Tomás de Aquino en su comentario In De Divinis Nominibus (c.XI lec.1, 888; ed. C. Pera, Turín/Roma 1950): la pax rerum significa una 'triple unión': una de las cosas consigo mismas (ad seipsas), una con las otras entidades (ad aliam), y una al único principio de la Paz (ad unum principium pacis), o sea Dios (idest ad Deum).

27 Entre ellos, y tal vez el más famoso, H.-U. von Balthasar, Herrlichkeit. Eine theologische Ästhetik, Vol.2, pp. 192sqq. 
toestablecimiento de la realidad antes de regresar como algo propio a su Creador. ${ }^{28}$ Quisiera llamar la atención al hecho de que esta ontología tripartita en su estructura es enteramente neoplatónica. En los neoplatónicos, encontramos estas mismas tres 'fases' ontológicas de procesión/descenso, detenimiento/recolección, y regreso/ascenso del ser

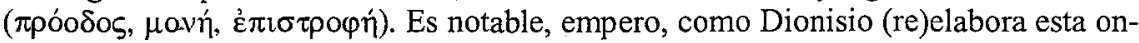
tología platónica: exclusivamente por la discusión de nombres divinos de la tradición judeo-cristiana, de teónimos biblicos.

- En este mismo contexto, es interesante comparar una famosa cita del poeta inglés Samuel Taylor Coleridge. En sus Memorials of Coleorton, describe el impacto que tuvo en él la lectura de los textos neoplatónicos. Dice textualmente del sistema metafísico encontrado en ellos: [es] «el despliegue más hermoso y ordenado de una filosofia que emprende la tarea de explicar la totalidad de las cosas estrictamente a través de un análisis de la autoconciencia, y a la vez construye en la mente un entero cosmos sirviéndose de nada más que de elementos proporcionados por la mente misma» ${ }^{29}$. Nótense, en esta observación de Coleridge, dos elementos: el análisis del mundo interior, psíquico como método; y la reconstrucción de la totalidad del ser a través de introspección y por elementos proporcionados por nada más que la mente humana.

Es una manera de conocer el mundo objetivo a partir y a través del mundo interior o sea: un método de entender no por tratar las cosas extramentales, sino por introspección y a través de la ordenada reconstrucción del cosmos entero a partir de un examen de los elementos constitutivos de la propia mente. Todo eso puede subsumirse al paralelismo de la ontología dionisiana con el acto de reflexión mental aducido antes.

Hay otra implicación, sin embargo, y esta toca una faceta del pensar dionisiano correspondiente a otro tratado, La teología mística. En éste, se describe de una manera muy rígida y casi dogmáticamente formalizada el camino espiritual del ser humano hacia la unión mística con la primera Causa, o sea Dios. Ahora bien, la unión mística se lleva a cabo, mejor dicho: 'se experimenta' en tres fases bien y aún rigurosamente definidas, según Dionisio ${ }^{30}$ : en la Teología mística, se habla 1. de una purificación men-

28 DN 704B-708B; en DN 704C, en especial, Dionisio deja en claro su concepto de una fase necesaria de cese de movimiento y de auto-establecimiento de las creaturas, hablando sobre sus rovói y de la 'pacificación' del flujo ontológico (como se verá más adelante en este artículo). Vale añadir que este también es un teorema bien conocido por los platónicos paganos, y que se encuentra aludido en Platón. Éste, en el Fedón (104d) enseña que la 'forma'

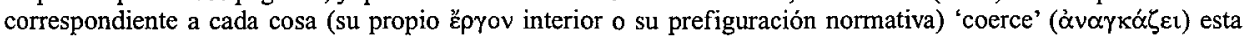
misma cosa a permanecer en su determinación esencial, y así la confine a un bien definido e imperturbado reposo ontológico. Asimismo, Plotino habla de que las entidades, al emerger del flujo ontológico del que proceden «no deben fluctuar, por así decir, en el indefinido, sino que deben ser fijados por límites y estabilidad ontológicos») (Enn. V.1[10].7,24f). - Que el auto-establecimiento como algo propio tiene valor y sentido en cuanto al retorno a Dios, se explica por diferentes motivos, entre los cuales se halla la discusión del mal en el cap. 4 de DN (713D-736B), que siempre ha sido subestimada como una intercalación un tanto fuera de propósito dentro del conjunto de la obra. En C. Schäfer, Unde Malum, pp. 440-452, he tratado de demostrar que es exactamente en su solución al problema del mal que Dionisio tiene que afirmar la autonomía y el status propio de las creaturas para que se las pueda considerar libres. Es esta, a su vez, la única forma de explicar cómo Dionisio puede afirmar la inocencia de Dios ante los males, ya que éstos deben atribuirse, entonces, a las desviaciones y los espontáneos errores de las creaturas.

29 En el original: «The most beautiful and orderly development of the philosophy which endeavours to explain all things by an analysis of consciousness, and builds up a world in the mind out of materials furnished by the mind itself, is to be found in the Platonic Theology of Proclus) (S.T. Coleridge, Memorials of Coleorton II, January

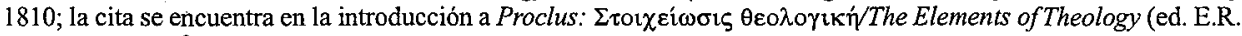
Dodds), Oxford 21963 , p. xxxiii).

30 Y. de Andia, Henosis. L'union à Dieu chez Denys l'Aréopagite, Leiden 1996, identifica siete 'fases' dèl ascenso místico (compárese asimismo Y. de Andia, La divinisation de l'homme selon Denys. En: Diotima 23 (1995), pp. 86-91. En cambio, los estudios de W. Beierwaltes (Dionysios Areopagites - ein christlicher Proklos? En: W. Beierwaltes: Platonismus im Christentum, Francfort 1998, pp. 44-83) y de J. Vanneste (La doctrine des trois voies dans la Théologie Mystique du Pseudo-Denys l'Aréopagite. En: Studia Patristica 8 [ed. F.L. Cross], Berlín 1966, pp. 462-467) identifican — aunque de diferente manera - tres 'fases'. Me atengo a ellos. 
tal, concebida como iniciativa humana y como una actividad de la razón con el fin de autolimitarse y vaciarse; 2 . de un subsiguiente cese de toda actividad mental como el último grado y como el resultado del antedicho ejercicio de autolimitación concéntrica; y 3. finalmente la repleción de la mente así vaciada y tranquila por la luz divina, fase que correspondería a la unión mistica. ${ }^{31}$

Todo esto puede parecer bastante dudoso, tal vez hasta descabellado y como tantos otros escépticos de la mística fillosófica no puedo excluir con certeza que así sea. Eso sí, dejando aparte consideraciones sobre el inmenso impacto que este rígido procedimiento de mística filosófica tuvo en la historia, y no considerando el carácter altamente especulativo y de ascética sobriedad, todo lo cual podría testimoniar a favor de la mística como método filosófico. Pues, desconsiderando todo esto, la descripción formal del ascenso místico en Dionisio es interesante porque refleja fidedignamente el movimiento ontológico tripartito del tratado DN. La fase de la actividad de autovaciamiento mental corresponde a la irradiación y auto-entrega divina en la poderosa procesión ontológica. El cese de la actividad y la tranquilidad de la mente corresponde al cesamiento y asentamiento del flujo ontológico. Y, por supuesto, la última fase de la iluminada unión mistica correspondería al retorno ontológico de la creación a Dios.

5.

Creo menester un breve resǔmen intermedio de la teo-ontología dionisiana: según un adagio acuñado por Goethe, uno sólo entiende con claridad lo que uno mismo es capaz de producir. ${ }^{32}$ Dionisio hace exactamente eso: reproduce el cosmos entero de la creación divina en la mente humana, paralelizando el acto reflexivo con la ontología de procesión, detenimiento y retorno. Como si el mundo fuera un pensamiento divino, y el pensamiento divino se pudiera repetir en cierta medida en el pensar humano. Es este también el punto de enganche para la mística dionisiana que describe precisamente la instantánea coincidencia del intelecto humano con el 'intelecto' divino. En Dionisio, es como si la mente humana alcanzara a contemplar el mundo a través de los ojos de Dios. — ¿Qué no verá aquél que ve a Quien todo lo ve? reza un refrán de la gnoseología teológica que se encuentra en San Gregorio Magno y que Santo Tomás de Aquino repite varias veces. ${ }^{33}$

Considerando estos antecedentes, es imposible dar más de un mero esbozo de esta elaboradísima teo-ontología dionisiana en el limitado espacio del presente estudio. No se me exija dar una exhaustiva introspección a la mente divina dentro de este margen. Dentro de la exposición del sistema dionisiano, sin embargo, quisiera resaltar y detenerme más detalladamente en sólo dos de los Nombres Divinos, a saber: Justicia y Paz, cuyas obvias connotaciones 'éticopolíticas' (si se las quiere llamar así) permitirán esclarecer la relación entre la experiencia social de la vida humana comunitaria con el gran proyecto metafísico del Areopagita. Vale señalar que al asumir (algunos dirían al 'usurpar') el nombre de 'Dionisio el Areopagita', el autor se decide por adoptar la perspectiva de un 'jurista converso'. Este detalle deja de ser una mera e insignificante circunstancia de la ficción o auto-estilización literaria en el momento de interpretarla como constituyente en la elaboración del sistema filosófico del ignoto autor. En lo siguiente, servirá como base de la discusión de estos dos teónimos en particular.

31 Esta unión es, en efecto, la forma de conocer a Dios el 'hiperóntico' por una forma de conocimiento que

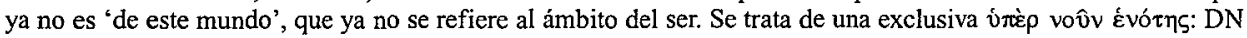
$588 \mathrm{D}$.

32 J.W. Goethe, Italienische Reise, Bericht zum September 1787 in Rom. En: J.W. von Goethe, Italienische Reise [ed. H. von Einem], Munich ${ }^{9} 1978$ ).

33 En la Quaestio disputata de veritate, Tomás de Aquino atribuye esta cita a Gregorio Magno: quid est quod non videant qui videntem omnia vident? ( $Q$ uaestio disputata de veritate q.2 a.2 solutio; ed. Leonina XXII, Roma 1970). 
De acuerdo con el esquema de la filosofia dionisiana, ambos teónimos, tanto Justicia como Paz, pertenecen a la segunda fase equivalente al detenimiento del flujo ontológico. Lo que tienen que explicar es, por ende, como el flujo ontológico procedente de Dios comoila única Causa del ser, se detiene y se asienta en diferentes niveles, formando de esta manera el universo de las entidades creadas.

En este sentido, Dionisio, en tratar el teónimo Justicia, se sirve del concepto tradicional de justicia legal o político. En especial de la definición de la justicia distributiva como la ha expuesto Aristóteles en el libro V de la Ética a Nicómaco. ${ }^{34}$ La idea básica de esta definición es la de 'darle lo correspondiente a cada uno', de concederle a cada cual lo que le conviene y que merece como individuo y en vista a lo que conviene al conjunto o, en el caso de la justicia legal, a la sociedad, a la comunidad política. En el ámbito político-legal, el esquema es relativamente transparente: lo que le corresponde al trabajador es una remuneración equivalente a sus esfuerzos; al niño le corresponden tutela, educación, etc.; al criminal un castigo de acuerdo al crimen cometido. Un mundo estrietamente regido por este concepto sería, en teoría, un mundo justo. No hablemos aquí sobre cómo llevar a cabo o a la práctica esta idea fundamental de justicia. Pero en lo formal debería estar clara. Lo correspondiente siempre se define diferentemente según la variación del sujeto tratado con justicia: al niño le corresponde tutela, no al adulto (éste más bien la rechazaría como una forma de 'paternalismo'); al asesino le corresponde la sentencia de cadena perpetua, no a quien cruce la calle con el semáforo en rojo.

Ese mismo esquema qué én el ámbito político-legal nos es conocido y que aceptamos empáticamente en el trato humano, es transferido por Dionisio a su gran planteamiento ontológico: la Justicia divina, o mejor dicho Dios concebido enteramente como justicia, asegura que todo en el mundo reciba su 'porción correspondiente' de ser (por así decir), estableciendo de esta manera tanto la repleción de cada una de las entidades individualmente como el orden ontológico del universo entero. Entre las consideraciones dionisianas sobre el tema, la siguiente servirá bien de ejemplo:

Por su justicia también es alabado Dios porque concede a todos [los seres] proporción, hermosura, composición, armonía y orden según conviene a todos. Reparte y establece de antemano sus órdenes a todos los seres, según verdadera y justísima determinación. Es el principio de actividad de cada cual. La justicia divina ordena las cosas y las determina, las conserva libres de mezcla y confusión con las demás, concede a todas según corresponde la dignidad de cada una de ellas. ${ }^{35}$

El 'sistema distributivo' es el mismo de la justicia cotidiana: hay seres a los que les corresponde una mayor porción o intensidad de ser que a otros. Tres intensidades diferentes ya se desprenden del cuadro de los teónimos dionisianos: mero ser, ser viviente, vida intelectiva. ${ }^{36}$ A las piedras, por ejemplo, les corresponde el ser - simplemente existen-, pero no las in-

34 Pero no sólo se encuentra en el siempre más explícito Aristóteles. También Platón conoce el concepto y lo deja entrever en la República y en el Gorgias (508ab, sobre todo). Los platónicos subsiguientes habían retomado la idea de una justicia de partes iguales según razón matemática y la habían aplicado (de acuerdo con lo que hallaron en los diálogos platónicos) al conjunto de la realidad. Es por eso que en Plutarco encontramos la visión del Dios de

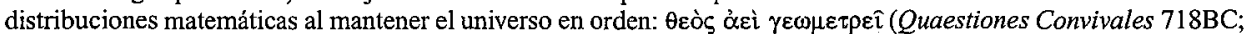
en: Plutarchi Moralia vol. IV, ed. C. Hubert, Stuttgart ${ }^{2} 1971$ ).

35 DN 893D-896A. Como en todas las demás citas castellanas de DN, la traducción es de T. Martín-Lunas.

36 Una tripartición gradual que también se encuentra en San Agustín, Sermo 43 3,4 (PL 38, 255/56): habemus ipsum esse cum lignis et lapidibus, vivere cum arboribus, sentire cum bestiis, intellegere cum angelis. En Agustín, es un topos recurrente; una explicación refinada se halla en De civitate Dei XI 16 (PL 41, 331). La inspiración textual para los platónicos de cada época e índole fue una vez más el ineludible Platón mismo, sobre todo en el Sofista (248e-249a) y en el Timeo (39e). En Proclo, se encuentra una versión invertida de esta gradación ontológica

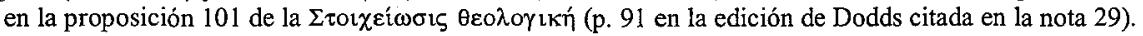


tensificaciones ontológicas de vida e intelecto; mientras que a los seres humanos y a los ángeles, les corresponde el ser, más vida e intelecto, pero también de forma diferente: ser corpóreo a los humanos, incorpóreo a los ángeles; intelecto discursivo a los humanos, intelecto intuitivo a los ángeles - y también dentro de los diferentes géneros y especies de seres, todas estas intensificaciones, variaciones y gradaciones se dan de manera diferente entre los individuos. (De hecho, el CD contiene un tratado dedicado exclusivamente a las gradaciones de los ángeles, Las jerarquías celestiales. ${ }^{37}$ ) La benéfica circunstancia que cada ser reciba todo lo que puede recibir (premisa de la $\mu$ ovń de los seres y de su paz consigo mismo) y que al mismo tiempo unos seres reciban más que otros (premisa de los diferentes grados de seres que conforman el universo estable) revoca la linda y famosísima 'paradoja' - enunciada por Teresa de Ávila ante un problema semejante- de las, botellas todas llenas hasta no poder más y sin embargo unas 'más llenas' que otras por su î, yor volúmen.

Es la Justicia divina, pues, o Dios siendo Justicia en superabundancia, que administra y reparte el ser de tal manera por el mundo que éste forme un cosmos armónico y equilibrado. Dios como Justicia del mundo, o sea la autoentrega de Dios como Justicia en la creación, pone el universo en perfecto balance, y lo mantiene así en equilibrio a la perfección por la justa distribución del ser. No es por coincidencia que Dionisio, en su descripción de la Justicia divina, recurra a la imagen de la balanza que hasta hoy en día conservamos como símbolo de justicia: habla de la 'archidivina balanza' de los seres. ${ }^{38} \mathrm{De}$ ahí también se entrevé el motivo por el que Dionisio presenta una ontología en términos teológicos, en 'nombres divinos'. Y de ahí también se empieza a entender la conexión entre los teónimos y el papel que juegan en el paulatino desenvolvimiento de la ontología dionisiana: Dios como Sabiduría (cap. 7, DN 865B869B) conoce y sabe lo apropiado para cada ser y para la totalidad de los seres. Como Poder (cap. 8, inicio; DN 889C-893D), Dios puede lo que sabe, y como Justicia (cap. 8, medio; DN 896A-C), se implementa a todo lo que es. -De este modo, Dionisio puede seguir afirmando que en su teo-ontología, la primera Causa, aunque no sea idéntica a la creación (presupuesto que se implementa por el dogma antipanteísta cristiano), trasluce indisminuidamente por cada parte de la realidad óntica, iluminándola de ser.

Una vez entendida la aplicación de esta idea principal, también es más fácil comprender la 'Paz' como teónimo dentro de la ontología dionisiana (DN 948D-953B). 'Paz' es el nombre divino que concluye y resume la secuencia de teónimos correspondientes al detenimiento del flujo ontológico (cap. 7-11). Y 'funciona', por así decir, a la misma manera de la 'Justicia'. O sea: partiendo de nuestra experiencia humana de paz política o social, Dionisio elabora un concepto de paz ontológica que a su vez dejará vislumbrar una idea de Dios como la paz del mundo. Como justicia, Dios pone en equilibrio las diferentes intensidades y gradaciones ontológicas, armonizándolas y jerarquizándolas para formar el cosmos ordenado de las cosas creadas. ${ }^{39}$ Siendo paz consigo mismo, la paz define la individualidad de los seres y a la vez une los seres individuales para que puedan ser un cosmos de perfectas jerarquías, de balances, propiedades y particularidades que no se exterminan mútumente, sino que se conjugan para formar una unidad cósmica símbolo de la unidad de los seres con El que les confirió esta doble y ahora triple paz.

37 El término 'jerarquía', en este sentido, parece ser acuñado por Dionisio: cf. J. Stiglmayr, Über die Termini Hierarch und Hierarchie. En: Zeitschrift für Katholische Theologie 22 (1898), pp. 180-187.

38 DN 589A; posiblemente, la expresión es inspirada por Proverbios 16,11.

39 Cf. DN 948D: «Además, por participación de la paz divina, las primeras fuerzas conciliadoras se unen ante todo unas con otras y con la fuente única de paz universal. Luego, estas fuerzas hacen que las de rango inferior se unan consigo mismas, entre ellas, y con el único y más perfecto Principio y Autor de toda paz. Cuando El viene individualmente a cada uno de estos seres consolida la unión como si pusiera cerraduras y vasallos; une lo que está dividido, todo lo define, determina y robustece; no permite que las cosas divididas hasta el infinito permanezcan dispersas caóticamente, ni que fuera de la unidad confusamente se mezclen entre sí»). 
Dirá alguno: «¿Cómo es que todas las cosas apetecen la paz? Hay muchas que gozan de ser distintas y aun diversas, nunca quieren por sí mismas estar en paz». Esto es cierto si al hablar así se afirma que la diversidad y distinción se refieren a la individualidad de cada cosa y del hecho de que nada quiere perder de la propia individualidad. Pero eso mismo es un deseo de paz. Porque todos los seres desean tener paz consigo mismos, estar unidos y permanecer ellos mismos y todas sus cosas inmóviles e ilesos. Y es perfecta aquella paz, consevando sin confundir la individualidad de cada cual, dando providencias que aseguren todas las cosas en paz y exentas de confusión interna o de fuera. Ella es la que establece todo con poder estable, indeficiente, para su paz e inmovilidad. (DN 952B952C)

La paz representa, resume y describe esta armonía aplacada que es el epítome de la $\mu$ ovoí, del detenimiento de las cosas al reposar y establecerse como propias. Sin embargo, intensifica y desesquematiza esta idea de armonía ontológica. Por ello, Dionisio insiste en que esta paz es una paz perfecta, una paz de seres ilesos en paz consigo mismos individualmente y respecto al todo. ¿Cuál es el gran logro de esta paz?

Daré un ejemplo: la armonía que rige el reino animal, equilibrando sus fuerzas y funcionamientos, se nos presenta, entre otras cosas, como la armonía de la araña comiéndose la mosca, del sapo comiéndose la araña, del pájaro comiéndose al sapo, del lobo comiéndose el pájaro, etc. En otras palabras: en total, como un equilibrio de presas y fieras, de huidas y persecuciones, de venenos, mimicris, colmillos y garras en un gran ciclo alimenticio despiadado. Es un equilibrio armónico fascinante, con profundo sentido biológico, admirable y de correspondencias perfectas que mantienen el mundo animal en un asombroso estado de eternas congruencias. Sin embargo, es completado y superado por el concepto de la paz de Dios que Dionisio nos presenta como organizando el cosmos de los seres. Compárese solamente la antedicha descripción de las armonías perfectas naturales con la visión de la Paz divina en el profeta Isaías (11,5-9): «el lobo habitará con el cordero, el tigre se acostará junto al cabrito, el ternero comerá al lado del león y un niño los cuidará. La vaca y el oso pastarán en compañía y sus crías reposarán juntas», etc. Y a propósito de la relación entre Justicia y Paz, también en esta visión bíblica, la paz depende de la armonía establecida por la Justicia: Isaías comienza este pasaje sobre la paz mesiánica con la afirmación de la justicia que precede el orden pacífico del universo. Si la armonía es la flor de la Justicia, la paz es su fruto. Aquí también, entonces, la experiencia humana que la paz es obra y fruto de la justicia, da la clave para la teoría ontológica y la especulación teológica. $O$, al revés: Dios es inefable, y la mente humana nunca lo alcanza. Pero la metodología dionisiana, al volverse hacia los teónimos bíblicos, permite que lo captemos a través de su presencia ontológica en el mundo óntico.

Vale resaltar que el tema de la paz se puede considerar una 'innovación' cristiana en la filosofía platónica. Al menos en el sentido señalado. Por supuesto que Platón habla de la paz en numerosas ocasiones, pero principalmente en el sentido político y social. En cuanto a la metafisica, un serio intento de describir la subestructura ontológica del mundo en términos de paz, parece que pertenece más que nada a los autores cristianos. Dionisio es un buen ejemplo de ello, otro es San Agustín en su famosa discusión de la paz que domina gran parte del libro XIX de la Ciudad de Dios. En Plotino, en cambio, el neoplatónico por antonomasia, la palabra 'paz' se encuentra una sola vez en el total de sus obras: Plotino discute armonías y equilibrios, pero no la paz. En Proclo, el tema de la paz se encuentra más a menudo (aunque no mucho: eipńv $\eta$ y cognados aparecen 31 veces en el vasto corpus de su obra conservada); pero casi siempre en contextos más que nada éticos.

\section{6.}

Para concluir, algunas consideraciones adicionales acerca de los teónimos Justicia y Paz. Sobre todo en cuanto a sus connotaciones gnoseológicas y en cuanto a sus aportes para esclarecer el método de los teónimos en la filosofia de Dionisio. En verdad, las experiencias que te- 
nemos humanamente tanto de paz como de justicia son bastante insatisfactorias y pocas veces convincentes. La justicia estatal y de las cortes o tan sólo de las aulas de clase y de las evaluaciones de trabajo es casi siempre defectuosa y pervertida al punto de desvirtuarse a sí misma por completo. Lo mismo con la paz: la paz política, si es que llegamos a conocerla en esta vida, la experimentamos como una delicada tregua temporal y siempre amenazada, la paz doméstica es muchas veces percibida como una paz opresiva, y es significativo que le deseamos al muerto después de todo eso 'paz en su tumba' - por lo menos en su tumba, pero ¡qué concepto lúgubre e insatisfactorio de paz! Es muy probable que nunca haya existido ser humano que haya vivido en una sociedad enteramente justa y/o pacífica. De la paz mesiánica descrita por Isaí- as ni hablaré. Esto en cuanto a nuestra realidad política o cotidiana. Y sin embargo, parece que todos tenemos un concepto relativamente claro y un anhelo muy concreto de paz y justicia, y de paz y justicia perfecta e incondicionalmente hablando.

No esquivemos la gran pregunta: ¿Cómo podemos tener este anhelo de algo perfecto si experimentamos y conocemos este algo solamente en un estado muy defectuoso y decepcionante? ¿De dónde obtuvimos, siendo seres contingentes, un concepto perfecto de paz y de justicia? ¿Qué sentido tiene el anhelo de algo humanamente inalcanzable? ¿Por qué entendemos a Isaías y su planteamiento de paz utópico (en el sentido etimológico)?

Para Dionisio, la razón de todo esto es doble:

Por un lado, justicia y paz en su forma absoluta son la subestructura ontológica del mundo óntico al que pertenecemos. Dios es la Justicia absoluta y la Paz absoluta. El mundo, siendo nada más (¡ni nada menos!) que la irradiación y autoentrega de Dios, conserva, por ende, la justicia y la paz como principios de su propio ser. Aunque, claro está, de una forma no-absoluta sino contingente, ya que el mundo es una teofanía, pero no es idéntico a Dios. Tanto más así en el caso del mundo humano. De ahí se comprende por qué conservamos una idea de la Justicia perfecta y la Paz absoluta: no sólo pertenecemos a un mundo humano de paces deficientes y justicias penosas, sino también formamos parte de un universo que a través del planteamiento ontológico dionisiano se entiende como una epifanía (incluso material) de la Justicia misma y de la Paz misma en el sentido indicado más adelante. Al igual que Dios se ha hecho hombre en el mundo, manifestándose de una manera palpable, Él también se hace Justicia y Paz en el mundo manifiestamente. Tal como San Pablo escribió a los romanos: Dios se ha manifestado a los pueblos de diferente manera, pero desde el inicio de los tiempos a todos los hombres en uso de la razón a través de su Creación (Rom 1,19sqq).

Por otro lado, Dionisio ve el sentido y la razón del entendimiento de y del anhelo por la Justicia absoluta y la Paz absoluta en el ascenso de todo ser hacia la unión con el Uno. Esta es la causa final que Dionisio ofrece para entender nuestro deseo de lo absoluto siendo contingentes. Los humanos, al igual que cada ser creado, formamos parte de todo el desarrollo ontológico tripartito. Tal como somos, nos falta, después de haber sido creados y de haber sido definidos ontológicamente, la última fase del retorno a la causa prima. Y estructuralmente, sentimos esta falta, según Diönisio. A diferencia de los seres no-intelectuales, sin embargo, en los seres dotados de intelecto, y más aun de libre albedrío, este retorno que nos hace falta y que aspiramos para completar nuestro (por así decir) destino ontológico, debe corresponder a una libre iniciativa del ser creado. De otro modo, no correspondería a la naturaleza racional y libre, y el retorno a Dios sería una violación de la naturaleza en vez de ser su perfección. Para esta libre iniciativa, sin embargo, Dios nos 'da una mano' 40 : nos creó de tal forma que podemos entender la realidad mundana como Su teofanía, y para que, por esta vía, obtengamos una noción de Dios. De un Dios, Quien es la Justicia misma y la Paz absoluta. A través de esta noción y de este entendimiento, queda claro que el anhelo libre de retorno puede partir de nuestra ex- 
periencia cotidiana, superándola, y de nuestras facultades intelectivas que descubren la Justicia y la Paz absolutas como Causa de la realidad que es Su epifanía.

\section{7.}

Un breve epílogo: el tratado dionisiano DN nos introduce a una teo-ontología cuyo desenvolvimiento se presenta en tres 'fases' o 'etapas'. DDe acuerdo con la filosofia (neo)platónica subyacente a, o más bien: conscientemente imitada en todo este desenvolvimiento, el Areopagita (al estilo del neoplatonismo en Coleridge) «emprende la tarea de explicar la totalidad de las cosas estrictamente a través de un análisis de la autoconciencia, y a la vez construye en la mente un entero cosmos sirviéndose de nada más que de elementos proporcionados por la mente misma». La teo-ontología dionisiana se puede describir, entonces, con la ayuda de la experiencia intramental reflexiva, ya que el esquema de la procesión del ser desde Dios, de su detenimiento y de su regreso a Dios, es comparable, en más de un aspecto (aunque no en todos), al acto de generar o formar un pensamiento, contemplarlo, y reintegrárselo, que llamamos reflexión. $\mathrm{O}$, en una perspectiva un poco más refinada pero menos objetiva, a las fases de autovaciamiento, vaciedad y repleción recorridas por el pensador místico.

Forma parte de esta intricada teo-ontología el que para su descripción, Dionisio recurra exclusivamente al medio de los nombres divinos. En vez de hablar de procesión ontológica o creación, habla del 'Bien' que se autocomunica y se dispersa. En vez de hablar de un detenimiento del flujo ontológico, habla de 'Poder', de la balanza cósmica de la 'Justicia', y de la 'Paz' que es el paradigma de la unión de todos los seres y a que corresponden en lo más íntimo de su existencia. En vez de hablar sobre el retorno de todo a Dios o de la apocatástasis de la creación, habla de Dios que como Único permanece presente en todo y Quien todo lo subsume como Uno, siendo 'Rey de reyes', 'Alpha' y 'Omega', y la última 'Perfección' de todo que es y que Lo anhela. A la vez, Dionisio reconcilia estos teónimos bíblicos metódicamente con la terminología platónica - como en el caso de los nombres 'parmenideos' del capítulo 9- superándola, por un lado — como en el caso visto de la 'Paz' - pero siempre apuntando hacia el fin de su empeño doctrinal: demostrar que las enseñanzas de la sabiduría pagana y las verdades de la fe cristiana no solamente se pueden armonizar, sino que se pueden considerar las unas el suplemento de las otras, ya metódicamente, ya en contenidos, y que a la final expresan lo mismo.

De ahí también se podrá, tal vez, comprender con más claridad el uso — si bien siempre un poco descarado - del pseudónimo (o quizás mejor: del alónimo) 'Dionisio Areopagita': de la misma manera que los teónimos expresan a Dios según nos es conocido y según lo experimentamos a través de su creación (y sólo en lo que El piensa conveniente que sepamos) sin que en última instancia podamos revelar Quién y cómo es en verdad, el alónimo del Areopagita nos obliga a leer sus escritos como son y de acuerdo con la pretensión con la cual han llegado a nosotros, o sea: como el pensamiento de un autor cristiano cuyo objetivo es la proclamación del 'Dios desconocido' a los paganos a través de le fe cristiana, nombrándolo en teónimos bíblicos. En su tratado DN, Dionisio completa y lleva a cabo la pretensión paulina de comuni-

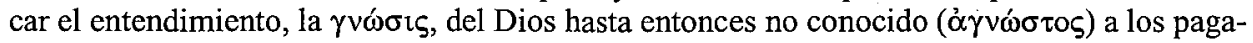
nos filosóficamente enseñados, quienes, según el capítulo 17 de los Hechos de los Apóstoles, se afanaron en entender ( $\beta o v \lambda o ́ \mu \varepsilon v o r ~ \gamma v \hat{\omega} v \alpha \mathfrak{l}$ ). Para ello, empero, Dionisio se sirve de la filosofía neoplatónica, o sea de un medio de expresión y una forma de pensar que para su época representa la cúspide de la indagación pagana en materias de entender el misterio divino. El alónimo del Dionisio Areopagita bíblico, le permite a nuestro autor confesar y enfatizar su pertenencia a ambos bandos reconciliados aquí: como Areopagita, es un alto representante de la cultura helénica y la ha absorbido antes de su primer encuentro con el cristianismo; como seguidor de San Pablo, se nos presenta como un cristiano de primera hora que conoció la doctrina apostólica directamente y sin mediaciones falseantes. Como intelectual converso, profesa la programática tarea de ponerle 'nombre' al anónimo Dios de la sabiduría pagana, 
rescatándolo de su anonimato y cruzando la última frontera que la especulación filosófica no había cruzado. A la vez, al exponer las verdades cristianas a través de un pensamiento enteramente platónico, se empeña en seguir a su maestro apostólico quien en su Carta a los Romanos enseñó que quienes no cometen el error de juzgar inútil el conocimiento de Dios, pueden llegar al conocimiento de Dios por el 'camino griego' de la razón que sin conocer las verdades reveladas pudo haber alcanzado a entender a Dios a través de sus manifestaciones (Rom 1,28 y 19sq.).

Christian Schäfer Institut für Philosophie Universität Regensburg D-93040 Regensburg 